Fordham Law School

FLASH: The Fordham Law Archive of Scholarship and History

Faculty Scholarship

2020

Special Education Disparities Are Social Determinants of Health: A Role for Medical-Legal Partnerships

Karen Bonuck

Albert Einstein College of Medicine

Leah Hill

Fordham University School of Law, Ihill@fordham.edu

Follow this and additional works at: https://ir.lawnet.fordham.edu/faculty_scholarship

Part of the Education Law Commons

Recommended Citation

Karen Bonuck and Leah Hill, Special Education Disparities Are Social Determinants of Health: A Role for Medical-Legal Partnerships, 14 Progress in Community Health Partnerships: Research, Education, and Action 251 (2020)

Available at: https://ir.lawnet.fordham.edu/faculty_scholarship/1115

This Article is brought to you for free and open access by FLASH: The Fordham Law Archive of Scholarship and History. It has been accepted for inclusion in Faculty Scholarship by an authorized administrator of FLASH: The Fordham Law Archive of Scholarship and History. For more information, please contact tmelnick@law.fordham.edu. 


\title{
Special Education Disparities Are Social Determinants of Health: A Role For Medical-Legal Partnerships
}

\author{
Karen Bonuck, $\mathrm{PhD}^{1,2}$, and Leah Aileen Hill, $\mathrm{JD}^{3}$ \\ (1) Department of Family and Social Medicine, (2) University Center of Excellence in Developmental Disabilities, Albert Einstein College of Medicine; \\ (3) Fordham University School of Law \\ Submitted 14 March 2019, revised 23 November 2019, accepted 19 January 2020
}

Abstract

Problem: Education is a key social determinant of health. The federal Individuals with Disabilities Education Act (IDEA) purportedly affords children the right to a free and appropriate education. Yet, racial, ethnic, and economic disparities exist regarding appropriate identification and classification of children with needs for special education, and access to services.

Purpose: This article first highlights gaps and disparities in special educational services, and their structural linkage to poverty. The second section describe the first years of a medical-legal collaboration between a University Center of Excellence in Developmental Disabilities (UCEDD) and Fordham University, focused on special education.
Key Points: The collaboration's interdisciplinary training activities increased practical knowledge for law students and UCEDD clinicians. A legal clinic for UCEDD families enabled Fordham students to apply their skills.

Conclusions: Because social determinants of health often lie beyond the medical domain, interdisciplinary collaborations are needed to remediate them.

Keywords

Education, government programs, sociology and social phenomena, child development, child, exceptional, disabled persons, parents
$\mathrm{E}$ ducation and poverty are major modifiable social determinants of health. ${ }^{1}$ This makes timely educational supports all the more critical for children with or at risk of disability. That was the idea behind the 1975 Education for All Handicapped Children Act, which was amended and renamed the IDEA in 1990. This landmark civil rights legislation in the United States provides federal money to states for the education of children with disabilities. To qualify, federal law requires that a child have a disability that "adversely affects" their educational performance. Although states have flexibility in how they implement the act (e.g., criteria used to define a learning disability), they must afford protections that meet or exceed the federal law. IDEA requires states have in place policies that ensure children with disabilities are identified and evaluated, and that eligible children receive special education and related services (hereafter, special education services) via an individualized educational program (IEP). Moreover, IDEA requires that school districts protect parents and their disabled children through various procedural safeguards. ${ }^{2}$ As of April 2018, $13 \%$ of children ages 3 through 21 years in public schools received IDEA. ${ }^{3}$

Although IDEA established a universal federal right to a free and appropriate public education for the nation's eligible children, gaps and disparities remain for children of color. One approach to mitigating these educational inequities lies in the growing medical-legal partnership (MLP) movement. MLPs integrate legal advocacy within health care settings to address the "health-harming needs of low-income and vulnerable populations." Educational accommodations for 
children with disabilities can have a lifelong impact, but are rarely the focus of such partnerships. ${ }^{4,5}$ Interdisciplinary partnerships such as that described here have significant potential to transform the lives of poor children, particularly children of color. ${ }^{6}$

This article is divided into two parts. First, we highlight current gaps and disparities in IDEA services. Second, we describe the first years of a medical-legal collaboration between a UCEDD and Fordham University, focused on special education. This collaboration meets some of the defined elements of MLPs (e.g., defined population, information sharing between health care and legal staff) but not others (e.g., formal agreement between legal and health care organizations). ${ }^{7,8}$ Thus, although not a formal MLP, the interdisciplinary training and services activities presented here describe steps toward one.

\section{GAPS IN SPECIAL EDUCATION}

In this section, we estimate gaps between who receives special education services vs. who is potentially eligible for them. We focus on 5 (of the 13) IDEA categories of disability that together represent $75 \%$ of students receiving IDEA services. The text in this section corresponds to the data in Table 1, Estimated Gaps in IDEA Services for Selected Diagnoses.

\section{Who Receives IDEA Services}

There were 58 million US children aged 3 to 17 enrolled in school in 2016 according to census data. ${ }^{9}$ Of these, 90\%about 52 million-were in public school according to the US Department of Education. ${ }^{3}$ In that year, the US Department of Education data identify 6.7 million public school students aged 3 to 21 years as having received IDEA Part B services for at least 1 of 13 disability categories (Part C applies to children under three years). These included specific learning disabilities (34\%), developmental disabilities which includes autism (9\%), intellectual disability (6\%) and developmental delay (6\%) and speech-language impairment (20\%). ${ }^{10}$

\section{Who May Be Eligible for IDEA Services}

Neither the US Department of Education, nor any other entity collects data on who is eligible for IDEA services. Therefore, we relied on data from the National Health Interview Survey, which administers face-to-face interviews in a nationally representative sample of households. For developmental disabilities, parents are asked whether a doctor or health care professional ever told them that their child had the disability. For specific learning disabilities, and speech-language impairments, questions are more qualitative, e.g., for language problems, the parent is asked if their child "had a problem learning, using or understanding words or sentence." Among 3- to 17-year-olds, 7\% were identified in this way as having developmental disabilities-defined as autism, intellectual disability, or developmental delay-as noted. ${ }^{11}$ (Developmental delay is not a standard disability category under IDEA Part B, though states may include it as one for children aged 3-9 years. $)^{12}$ The prevalence of speechlanguage impairment in National Health Interview Survey data is $8.0 \%,{ }^{10}$ and for specific learning disabilities it is $7.0 \%{ }^{13}$

\section{Gaps between Children Eligible versus Receiving IDEA Services}

We estimated gaps between the numbers of children potentially eligible vs. receiving services for the above diagnostic

\begin{tabular}{|lccc|}
\hline \multicolumn{4}{|c|}{ Table 1. Estimated Gaps in IDEA Services for Selected Diagnoses } \\
Estimates* & $\begin{array}{c}\text { Specific Learning } \\
\text { Disability }\end{array}$ & $\begin{array}{c}\text { Speech-Language } \\
\text { Impairment }\end{array}$ & $\begin{array}{c}\text { Developmental } \\
\text { Disability/Delay }\end{array}$ \\
\hline US prevalence rates, $\%$ & $7 \%^{11}$ & $8 \%^{10}$ & $7 \%^{9}$ \\
US prevalence in public schools, \# & 3.64 million & 4.16 million & 3.64 million $^{8}$ \\
IDEA participant by diagnostic service, $\%$ & $\left(0.07 \times 52.00\right.$ million $\left.^{8}\right)$ & $\left(0.08 \times 52.00\right.$ million $\left.^{8}\right)$ & $\left(0.07 \times 52.00\right.$ million $\left.^{8}\right)$ \\
IDEA participant by diagnostic service, \# & $34 \%^{3}$ & $20 \%^{3}$ & $21 \%^{3}$ \\
& 2.30 million & 1.20 million & 1.40 million $^{3}$ \\
Gap (b-c) & $\left(0.34 \times 6.70\right.$ million $\left.{ }^{3}\right)$ & $(0.20 \times 6.7$ million & $\left(0.21 \times 6.70\right.$ million $\left.^{3}\right)$ \\
\hline
\end{tabular}

* See denoted references in text for data sources. 
categories (Table 1). As we culled data from multiple sources, figures shown are for estimation purposes only. Applying US prevalence rates (a) to the public school population yields an estimate of the number of public school children with these disabilities (b). Applying the proportions of children in these IDEA services categories (c) to all children in IDEA programs indicates how many receive these IDEA services (d). The estimated gaps for just these disability categories alone are high: specific learning disabilities (1.34 million), speechlanguage impairment (2.96 million), and developmental disability/delay (2.0 million).

\section{DISPARITIES IN SPECIAL EDUCATION}

Poverty underlies gaps in education services. ${ }^{14}$ Since IDEA's inception, its federal funding share has never reached its legislatively authorized $40 \%$; it now averages closer to $18 \% .^{15}$ Thus, state and local governments are left to fund the bulk of special education in public school settings-at a time of increasing neighborhood economic segregation. In 1970, approximately $65 \%$ of families lived in mixed-income neighborhoods, compared to around $40 \%$ today. ${ }^{16}$ Income and racial disparities combine such that poor, non-White school districts receive $19 \%$, or about $\$ 2,600$ less per student than affluent white school districts. Even within poor school districts, there is an $11 \%$ funding gap $(\$ 1,500)$ between White and non-White school districts. ${ }^{17}$ Not surprisingly, lowincome districts spend significantly less to educate a child with disabilities than middle- or high-income districts. ${ }^{18}$ This geography-school spending link disadvantages Black and Hispanic children, because they are three times more likely to be poor than White children. ${ }^{19}$

Apart from economic disparities, there are concerns about both under- and over-identification of minority children as having disabilities. ${ }^{20}$ One analysis of large datasets that control for individual student academic achievement, poverty, and school level characteristics found that Black and Hispanic children were underidentified (by approximately 50\%) as having disabilities during elementary, middle and high school, versus White children. ${ }^{21}$ Conversely, this analysis has been critiqued as being grounded in deficit discourses and assumptions. ${ }^{22}$ Federal regulations to ensure that children of color are not over-represented in special education or more harshly punished, were proposed in late 2016. In March
2019, a federal judge overruled Education Secretary Betsy DeVos's efforts to delay implementation ${ }^{23}$-an important step forward in reversing systemic racial discrimination in education. This rule, in part addresses disparities by type of disability. Racial/ethnic minority children, for example, are less likely to be diagnosed with attention deficit hyperactivity disorder (classified as an other health impairment under IDEA) than White children, ${ }^{24}$ but more likely to be identified with intellectual disability or emotional disturbance. ${ }^{25}$ While approximately $8 \%$ of 3 - to 17 -year-olds have speechlanguage impairments, more than one-third do not receive interventions. Disparities are greatest for non-Hispanic Black and Hispanic children, ${ }^{12}$ thus mirroring racial/ethnic disparities in children's health and health care use. ${ }^{26}$

\section{UCEDD-LAW SCHOOL PARTNERSHIP DEVELOPMENT}

The Rose F. Kennedy Children's Evaluation and Rehabilitation Center (RFK CERC) at Montefiore-Einstein is located in the Bronx, the nation's poorest congressional district. ${ }^{27}$ CERC, a multidisciplinary diagnostic and treatment center, hosts one of the nation's 67 University Centers of Excellence in Developmental Disabilities (UCEDDs.) Since 2017, our UCEDD has been collaborating with the Fordham University School of Law, primarily through its Family Advocacy Clinic (FAC). The collaboration was spearheaded by the authors: Dr. Bonuck directs the UCEDD at RFK CERC, and Professor Hill is on the faculty at Fordham Law, where she is Associate Dean for Experiential Education.

UCEDDs were established under Public Law 106-402 (The Developmental Disabilities Assistance and Bill of Rights Act of 2000 or "DD Act") to promote community inclusion, through: inter-disciplinary training, community training and technical assistance, research and dissemination. A needs assessment conducted for the UCEDD in 2017 highlighted gaps in parents' knowledge about special education rights and need for advocacy. Outreach to area law schools led to a Fordham faculty member whose work focuses on family law and clinical education (LH). Together UCEDD and Fordham faculty developed a 5-year plan goal: "To promote capacity building, advocacy, and systems change" via the potential creation of a MLP.

The medical and legal professions have long collaborated to address the upstream causes of poor health such as housing 
and education. The World Health Organization refers to these social determinants of health as "the conditions in which people are born, grow, work and age.” Medical-legal collaborations to address social determinants of health began in earnest in the United States during the 1960s civil rights movement. With a community health center's hiring of an attorney to "treat" legal problems. ${ }^{8}$ With growing recognition of social determinants of health impacts, health care organizations have begun screening patients for health-harming social and legal needs, and in some cases establishing MLPs to address them. ${ }^{7}$ Several MLPs that focus on low-income children with disabilities and their families are described in the literature. ${ }^{28,29}$

The FAC is 1 of 16 student practice clinics at Fordham University School of Law. Second- and third-year law students enroll in the FAC, a five-credit course with a seminar component and a practice component. The FAC is an interdisciplinary practice clinic in which law and social work students work side by side to solve client legal problems through direct legal representation and social service advocacy. Most clients seen by the FAC seek representation in IDEA cases. Students enrolled in the FAC participate in a weekly seminar that includes readings on applicable law, social science and professional skills coupled with classroom discussions. As part of the casework component, students represent clients at IDEA due process hearings under the supervision of law and social work faculty. Fordham's Clinical Program operates eleven of its clinics through Lincoln Square Legal Services, Inc., a nonprofit law firm created by Fordham University School of Law to allow faculty and students to provide professional legal services for low income clients through its clinical program.

\section{INTERDISCIPLINARY TRAINING}

One of our UCEDD's MLP objectives was to increase the cadre of disability-informed lawyers. Toward that end, our UCEDD and Fordham engaged in a series of bi-directional training sessions.

\section{Psychologist Presentations to FAC Seminar}

FAC students gain skills in, among other areas, reviewing and analyzing student records, researching and analyzing statutes and caselaw, interviewing and counseling clients, submitting evidence, and conducting administrative hearings.
Until our UCEDD-Fordham collaboration, the FAC seminar did not include a partnership with a multidisciplinary community provider who could provide, for example, dedicated training in how to interpret evaluations (e.g., psychological, academic, language) or exposure clinicians who serve as expert witnesses. A clinical psychologist and director of allied health training at RFK CERC presented to the FAC seminar early in its Spring semester (January 2018 and 2019). She described the RFK CERC's clinical programs, and evaluation process. Students reported increasing their knowledge about psychological, language, academic and developmental evaluations and tests.

\section{FAC Seminar Visit to RFK CERC}

The RFK CERC provides multidisciplinary assessment to children aged birth through 21 years. New patients are seen by a psychologist or social worker for an initial evaluation that includes reason for referral, history taking, and brief screenings. Recommendations for further neurodevelopmental, cognitive, behavioral, or other testing are made, and presented at a weekly multidisciplinary team meeting.

To deepen FAC students understanding of the clinical profile and testing protocols, they attended the 2-hour, school-aged team meeting at RFK CERC (February 2018 and 2019). One clinician from the team evaluating the child presents the case. Clinicians from developmental-behavioral pediatrics, psychology, social work, and speech-language pathology discuss the testing results, and plan for treatment. Law and social work students from the FAC met with RFK CERC clinicians before the meeting for discussion of the multidisciplinary team's process, and to allow the students to ask questions about different aspects of the evaluation process. After the meeting, RFK CERC clinicians offered an extensive debrief, which included an opportunity for FAC students and faculty to query the team on its discussions and decisions and share insights about the special education system gained from their work with clients.

\section{Grand Rounds at RFK CERC}

Clinicians and trainees from all disciplines attend a monthly 1 -hour grand rounds delivered by RFK CERC faculty or outside speakers. Topics range from clinical topic related to diagnosis and treatment, as well as policy issues. Though 
their clinic reports are often used to support advocacy for special education services, many on the RFK CERC staff were unaware of laws that affected how such reports were used in practice. Attorneys associated with the FAC seminar delivered a Grand Rounds on legal requirements for special education evaluations and assessments (January 2019). The presentation was well-received as evidenced by the number of clinicians who stayed after the allotted time to ask additional questions.

\section{Chinese Planning Council}

Under a grant from the state Department of Health, our UCEDD is working to increase family satisfaction with early intervention (IDEA, Part C) services. Given our catchment area's demographics, this includes outreach to Spanish- and Mandarin-speaking communities. A special education legal consultant to our UCEDD (discussed elsewhere in this article) delivered a well-received talk to parents at this New York City community center (July 2019), entitled “Transition from EI to Preschool Special Education Services.”

\section{LEGAL CLINIC}

To put the interdisciplinary training into practice, the Fordham and UCEDD teams planned a one-time legal clinic for RFK CERC families. The clinic was advertised as a 1-hour consultation, via English and Spanish flyers distributed to RFK CERC families, and at an annual parent workshop. It was organized, staffed, and conducted by student summer interns and faculty of Lincoln Square Legal Services, Inc. (LSLS). The authors created the structure for the one-day clinic. A bilingual LSLS attorney with expertise in special education law supervised three law students, beginning with a 30-minute phone screening to ascertain: the student's current situation, type of relief sought by family (i.e., could be provided under IDEA), any prior litigation with the New York City Department of Education, and so on. Five families were scheduled for consultations and asked to send any school or evaluation documents beforehand. Professional translators were provided.

Four of five scheduled families attended the consultation. Two sent documents beforehand, including one whose school faxed documents, after the family prompted the school. The other two families brought documents to the consultation. Consultations took place at the LSLS offices in Manhattan, despite concerns that parents would not travel from the Bronx. Two rising third year law students met in one consultation room, while the supervising attorney met with families in another room. All four families were Spanish speaking, so translators assisted in both rooms.

The cases reviewed by the clinic involved a range of students from 2 nd through 10 th graders. The legal teams reviewed their last few years IEPs and school evaluations, where available. In all of the cases that were reviewed, the students were quite behind academically and according to the supervising attorney, all appeared to have very strong legal claims. The families had quite limited experience working with an advocate or special education attorney. The legal teams identified a number of legal issues, the most common being disconnects between evaluations and school recommendations on the IEP, as well as IEP goals that were inconsistent with current levels of performance. For example, the legal team observed IEP goals that were set for higher level skills, despite the fact that students were reading years below grade level. The team also observed IEPs being drafted by teachers who did not work with the child.

The consultations were helpful to parents, who were largely unaware of free or low-cost services. The teams pointed out issues to parents that they would not normally see, like goals for students that were too broad or inconsistent with assessments. Without an attorney, parents found it difficult to obtain services or to change their children's IEP. The team referred families to free in litigation can recoup some of their attorney fees. The team also shared some websites and information about attorneys who would assist clients on this fee-shifting basis.

\section{On-Site Legal Pilot}

Building on the above, RFK CERC engaged the LSLS attorney as a special education legal consultant in July 2019, on a pilot basis. With UCEDD funding, he maintained office hours 2 days per week on RFK CERC's main floor, alongside multidisciplinary clinical staff that included: limited scope consultation to parents (document review, legal advice, referrals) and RFK CERC clinicians, and presentations at RFK CERC and in the community. This lawyer-in-residence enables quick response to family and clinician questions, and deepens the lawyer's understanding of patients' health 
challenges. ${ }^{7}$ Families, who were referred informally by RFK CERC clinicians, signed a limited scope retainer agreement. The attorney was accessible by phone and email throughout the week.

After 3 months, UCEDD leadership and the attorney met to evaluate progress. Though families and clinicians benefited from the lawyer-in-residence model, consultation needs did not align with the scheduled on-site days, resulting in open time on those days but spill-over onto the off-days. Furthermore, in addition to special education, it became clear that families had other civil legal needs, e.g., housing and family law. The attorney had recently attended a national MLP conference, where he noted many programs opted for an on-site nonlegal navigator to screen and refer patients to a network of legal resources. As of Fall 2019, the UCEDD was planning a survey to identify the predominant legal needs to guide the development of a network of free (e.g., pro bono) or low-cost legal services, and fundraising to support program costs.

\section{CONCLUSIONS}

Despite IDEA's guarantee of the right to a free and appropriate education for children with disabilities, gaps and disparities remain, Upwards of 6 million children are likely not receiving IDEA services for which they may be eligible. Disparities are particularly acute for poor families. This is because while IDEA provides for an individualized right, it is subject to private (vs. public) enforcement. Wealthier parents' informational advantages means they are more likely to know when their IDEA rights are violated: "Wealthier parents of children with disabilities are able to use the private enforcement system, or the threat (whether implicit or explicit) of private enforcement to obtain superior services and more ambitious IEPs." 30

The experiences of families served by the legal clinic underscore these economic disparities. Despite children being significantly behind, none were determined to be receiving free and appropriate education or had legal representation. One study found that nearly a third of children with chronic health needs did not ask for an IEP. Of those with an IEP, fewer than $60 \%$ of families were satisfied with it. ${ }^{5}$ Families seen in the legal clinic lacked knowledge of legal services available for free or at low cost. The US Department Education, Office of Special Education Programs funds a network of parent information centers. However, their websites are not fully multilingual, nor are they designed for readers with low literacy, and do not offer links to free/low cost legal services.

Reducing disparities in identification and access to special education is both a civil rights and health care issue for low-income communities of color. Law school-health care collaborations such as ours have roles to play on two levels. Most directly, they can offer meaningful community education to some families, along with cross-disciplinary training aimed at expanding the cadre of disability-informed lawyers for the future. At the policy level, emerging strategies such as legal epidemiology - the study of the impact and effectiveness of laws on health-can be deployed. ${ }^{31}$ Special education disparities reflect larger education, housing, child welfare, health care, and other policies. Partnerships such as the one described here can begin to address the structural inequalities that give rise to these disparities.

\section{REFERENCES}

1. McGill N. Education attainment linked to health throughout the lifespan: Exploring social determinants of health. The Nation's Health: A Publication of the American Public Health Association. 2016;46(6):1-19.

2. Lipkin PH, Okamoto J. The Individuals With Disabilities Education Act (IDEA) for children with special educational needs. Pediatrics. 2015;136(6):e1650-62.

3. US Department of Education. Enrollment trends. Digest of Education Statistics, 2016 (NCES 2017-094). Washington, DC: Author; 2018

4. Regenstein M TJ, Williamson A. The state of the medical-legal partnership field: Findings from the 2016 National Center for Medical-Legal Partnership Surveys. Washington, DC: George Washington University; 2017.

5. DeJong NA, Wood CT, Morreale MC, et al. Identifying social determinants of health and legal needs for children with special health care needs. Clin Pediatr. 2016;55(3):272-7.

6. Hill LA. Disrupting the trajectory: Representing disabled African American boys in a system designed to send them to prison. Fordham Urban Law Journal. 2017;45:201-39.

7. Regenstein M, Trott J, Williamson A, Theiss J. Addressing social determinants of health through medical-legal partnerships. Health Aff (Millwood). 2018;37(3):378-85.

8. Teitelbaum JB, Theiss J, Boufides CH. Striving for Health equity through medical, public health, and legal collaboration. J Law Med Ethics. 2019;47(2 Suppl):104-7.

9. US Census Bureau. Enrollment status of the population 3 years and over, by sex, age, race, Hispanic origin, foreign born, and foreign-born parentage. Washington, DC: Author; 2016. 
10. US Department of Education National Center for Education Statistics. The condition of education: Children and youth with disabilities. US Department of Education. Available from: https://nces.ed.gov/programs/coe/indicator_cgg.asp2018.

11. Zablotsky B, Black LI, Blumberg SJ. Estimated prevalence of children with diagnosed developmental disabilities in the United States, 2014-2016. NCHS Data Brief. 2017(291):1-8.

12. Black LI VA, Hoffman HJ. Communication disorders and use of intervention services among children aged 3-17 years: United States, 2012 [NCHS data brief, no. 205]. Hyattsville, MD: National Center For Health Statistics; 2015.

13. Institute of Medicine (US). Committee to Evaluate the Supplemental Security Income Disability Program for Children with Mental Disorders. Washington, DC: National Academies Press; 2015.

14. DeLucia L. Special education and poverty. University of Notre Dame. Fresh Writing: An Interactive Archive of Exemplary First Year Writing Projects Web site [updated 2018; cited 2018 Jun 16]. Available from: https://freshwriting.nd.edu/volumes/ 2015/essays/special-education-and-poverty.

15. National Council on Disability. Broken promises: The underfunding of IDEA [updated 2018; cited 2018 Jun 28]. Available from: https://ncd.gov/sites/default/files/NCD_Broken Promises_508.pdf.

16. Reardon SF BK. The dream revisited: No neighborhood is an island. New York, NY: New York University Furman Center; 2014.

17. EdBuild. \$23 billion [updated 2019 Feb; cited 2018 Mar 12]. Available from: https://edbuild.org/content/23-billion/full -report.pdf.

18. Chamber JPT, Esra P, Shkolnik J. How does spending on special education vary across districts? US Department of Education, Office of Special Education Programs [updated 2002]. Available from: www.air.org/sites/default/files/SEEP2How-Does-Spending-Vary-Districts.pdf.

19. US Department of Education. Status and trends in the education of racial and ethnic groups 2016 [updated 2016; cited 2018 Jul 1]. Available from: https://nces.ed.gov/ pubs2016/2016007.pdf.

20. US Department of Education: Office of Civil Rights. Dear colleague letter: Preventing racial discrimination in special education. Washington, DC: US Department of Education; 2016.

21. Morgan PFG, Hillemeier $M$ et al. Replicated evidence of racial and ethnic disparities in disability identification in U.S. schools. Educational Researcher. 2017;46(6).

22. Collins KM, Ferri B, Gallagher D, Samson J. Dangerous assumptions and unspoken limitations: A disability studies in education response to Morgan, Farkas, Hillemeier, Mattison, Maczuga, Li, and Cook (2015). Multiple Voices for Ethnically Diverse Exceptional Learners. 2016;16(1):4-16.

23. Meckler L. Betsy DeVos effort to delay special0ed regulations rejected by court. The Washington Post; 2019.

24. Morgan PL, Staff J, Hillemeier MM, Farkas G, Maczuga S. Racial and ethnic disparities in ADHD diagnosis from kindergarten to eighth grade. Pediatrics. 2013;132(1):85-93.

25. Togut TD. The Gestalt of the school-to-prison pipeline: The duality of overrepresentation of minorities in special education and racial disparity in school discipline on minorities. J Gender Soc Policy Law. 2011;20(1):163-81.

26. Flores G. Technical report-racial and ethnic disparities in the health and health care of children. Pediatrics. 2010;125(4): e979-e1020.

27. Foundation RWJ. How healthy is your community. County health rankings and roadmaps [updated 2018; cited 2018 Jun 18]. Available from: http://www.countyhealthrankings. org/app/new-york/2015/rankings/bronx/county/outcomes/ overall/snapshot.

28. Rosen Valverde JN, Backstrand J, Hills L, Tanuos H. Medicallegal partnership impact on parents' perceived stress: A pilot study. Behav Med. 2019;45(1):70-7.

29. Zisser AR vSM. Health, education, advocacy, and law: An innovative approach to improving outcomes for low-income children with intellectual and developmental disabilities. J Policy Pract Intellect Disabil. 2015;12(2):132-7.

30. Pasachoff E. Special education, poverty, and the limits of private enforcement. Notre Dame Law Review. 2011;86(2011).

31. Burris S, Ashe M, Levin D, Penn M, Larkin M. A Transdisciplinary approach to public health law: The emerging practice of legal epidemiology. Annu Rev Public Health. 2016; 37:135-48. 